\title{
Immunology and microbiology in Miami
}

\author{
Eckhard R. Podack
}

Published online: 16 November 2013

(C) Springer Science+Business Media New York 2013

Immunology and Microbiology in Miami is alive, well and strong. Miami is located in South Florida on the shore of warm and pleasant Biscayne Bay, a sailor's paradise, located at the northern end of the Gulf of Mexico. Miami is one of the few cities in the US within the subtropical zone, blessed with warm weather year round and surrounded by clear and warm blue waters. The water is user-friendly throughout the year for swimming, diving, sailing, kitesurfing or any other water sport one might like to do. The city is green with many palms and exotic plants and flowers, with exotic fruit and flowering trees, everything growing rapidly and abundantly - a paradise for gardeners. Tourists, snow birds from the North in winter, and many others throughout the year from all over the US and Europe come to enjoy the unique ambience of Miami and the diversity of the population. Little Haiti and Little Havana offer unique flavors of the cultural mix along with many other 'Latinos' from Central and South America. Europeans including Russians and Asians are also well represented.

The semitropical climate along with the diversity of population also brings a unique mix of unusual diseases including rare infections not often seen elsewhere in our country. The Leonard Miller School of Medicine of the University of Miami and the Jackson Memorial Hospital staffed primarily by University Physicians take care of these exotic diseases that offer at the same time unique materials for research in our department.

The Department of Microbiology and Immunology, as the name implies, has investigators specializing in research in pathogenic bacteria, in virology and in immunology. A total

E. R. Podack ( $\square)$

Miami, FL, USA

e-mail: ePodack@med.miami.edu
Eckhard R. Podack

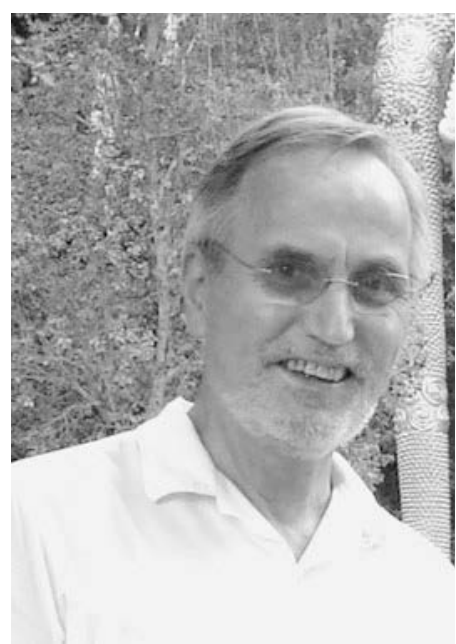

of 54 faculty members have primary or secondary appointments in the Department. Our research is primarily oriented toward basic discovery and understanding the biology of microbiology and immunology and what happens when they clash. How does the immune system recognize and kill microbes; how do the microbes counterattack or evade the immune response? What can we do to break antibiotic resistance? How can we influence this life and death struggle in our favor? What can we learn from anti-viral immunity that maybe similar and applicable to tumor immunity? Antiviral and anti-cancer vaccines and immunotherapy-do they follow similar principles, can we use the same vaccineimmunotherapy platform to fight viruses and cancer?

Why does the immune system allow cancers and how can we reverse this mistake? How does the immune system react to cancers? Tumors tend to generate specific tolerance as well as systemic immune suppression. What factors, which cells are the mediators? Can we use similar principles to generate antigen-specific tolerance to ameliorate auto immunity? What are the causes of autoimmunity, of autoaggressive disease? Can we create allo-specific tolerance-what are the molecular and cellular mechanisms? Does the immune system age and if we stop it do we stop aging in general?

Many autoimmune conditions are dramatically increasing-among them diabetes stands out. Together with the Diabetes Research Institute our faculty study the induction of tolerance to islet antigens and induction of tolerance to islet transplantation. Likewise in collaborations with Transplant Institute and Hematopoietic Stem Cell Transplantation group, we study how to prevent allogeneic transplant rejection or allogeneic graft versus host disease following stem cell transplantation.

Discoveries in Immunology and Microbiology are immediately useful for medical purposes and generate 
clinical benefit. Naturally, our faculty is engaged in many translational studies and research collaborations. Our Department is hosting the Center for AIDS Research (CFAR) studying HIV in all its virological, immunological and behavioral dimensions. We are actively involved in working for a cure and in the development of innovative vaccines to prevent and eradicate the disease.

Investigators from our Department are leading the Program of Tumor Immunology in the Sylvester Comprehensive Cancer Center. The studies include murine models of cancer to elucidate the molecular mechanisms of the immune response and of tumor-induced immune suppression. Our investigators translate basic research to clinical treatment in investigator initiated trials under their own IND and with vaccines produced in house. The novel vaccine technology based on ER chaperone gp96-Ig is also being developed by a Biotech company that recently had its successful IPO at NASDAQ in New York. An antibody developed in Miami has recently been approved by the FDA as Brentuximab Vedotin for Hodgkin's lymphoma and other CD30 positive tumors.

Our investigators also participate in and lead the program of Viral Oncology including AIDS-related tumors including Kaposi's sarcoma within the Sylvester Comprehensive Cancer Center. This unique program is sustained by the unique patient mix in Miami which does include a sizable group of HIV infected individuals.

The Miami Project to Cure Paralysis has evolved into a Center for Neuroscience research including Neuro-Immunology. Investigators are interested in Schwann cell transplantation to enhance spinal cord regeneration. Another focus is experimental allergic encephalitis as a model for multiple sclerosis believed to represent an autoimmune disease involving the central nervous system.

Pathogenic bacteria continue to be a constant threat in particular in children and the elderly. Investigators study the injection system that bacteria use to paralyze host cells. The factors being injected by bacteria and their function are of great interest as they may reveal soft spots of innate immune defense. Likewise other virulence mechanisms are investigated to enhance our understanding and enable us to take countermeasures. How does the innate and adaptive immune system defend us against the onslaught of all these microbes, viruses and bacteria? Three pore-forming proteins have been identified, killing-machines of innate and adaptive immunity that target extracellular bacteria, virusinfected and cancer cells and extracellular bacteria.

Finally, we all age and so does the immune system. Why and how? Can we stop it or at least delay the aging? And how would that affect longevity?

Of course an academic research program needs to be combined with educating and training the next generation of creative investigators and doctors. The department does its share of medical student teaching in microbiology and immunology and offers an 'Immunology Pathway' to interested Medical Students to increase and deepen their insights into immunological mechanisms in disease. We also sponsor a strong $\mathrm{PhD}$ and $\mathrm{MD} / \mathrm{PhD}$ graduate program educating and training bright and motivated science students for their doctoral thesis in Microbiology and Immunology. Unusual for a Medical School Department, we also teach and educate about 200 Microbiology and Immunology Majors in the Bachelor of Science program in the School of Arts and Sciences at the University of Miami. This teaching program provides our Graduate Students with Undergraduate Teaching experience in the Microbiology and Immunology Laboratory course. In return for its extra effort, the department receives part of the tuition funds as well as motivated students interested to learn experimental science.

So, Immunology and Microbiology is alive and strong and well in Miami. The book in front of you gives a snap shot of current activities in research that we hope you will enjoy as profitable reading. And contact us, we are always happy to discuss science and enter into new collaborative adventures of translation and discovery. 